Fanum

Sociológico
Forum Sociológico

Série II

17 | 2007

Envelhecimento activo. Um novo paradigma

\title{
Envelhecer com futuro
}

\section{Maria de Lourdes Quaresma}

\section{(2) OpenEdition}

\section{Journals}

Edição electrónica

URL: https://journals.openedition.org/sociologico/1618

DOI: 10.4000/sociologico.1618

ISSN: 2182-7427

\section{Editora}

CICS.NOVA - Centro Interdisciplinar de Ciências Sociais da Universidade Nova de Lisboa

Edição impressa

Data de publição: 1 janeiro 2007

Paginação: $37-42$

ISSN: 0872-8380

\section{Refêrencia eletrónica}

Maria de Lourdes Quaresma, «Envelhecer com futuro», Forum Sociológico [Online], 17 | 2007, posto online no dia 01 janeiro 2007, consultado o 31 março 2022. URL: http://journals.openedition.org/ sociologico/1618; DOI: https://doi.org/10.4000/sociologico.1618 


\title{
ENVELHECER COM FUTURO
}

\author{
Maria de Lourdes Quaresma \\ Investigadora em Gerontologia Social na Universidade Lusíada e na Universidade Lusófona, membro do CESNOVA \\ (mlquaresma@netcabo.pt)
}

\begin{abstract}
Resumo
Um novo olhar sobre o envelhecimento tem enfoque na componente oportunidade-conquista das sociedades contemporâneas, desconstruindo o paradigma centrado na variável idade. A partir de estudos nacionais e internacionais procura-se contribuir para a análise dos modelos de transição actividade profissional/reforma, relevando diferentes factores que influenciam e diferenciam estes processos. As políticas de envelhecimento activo são tratadas numa óptica de promoção de igualdade de oportunidades, com especial atenção para os percursos a montante da refor$\mathrm{ma}$, designadamente no acesso à formação. A garantia do direito a envelhecer com dignidade e segurança, projecto de uma vida adulta prolongada, incluindo as pessoas em situação de maior dificuldade constitui um outro eixo de análise, enquadrado nas recomendações e orientações internacionais neste âmbito.
\end{abstract}

Palavras-chave: Oportunidade, Empoderamento, Projecto, Participação

\begin{abstract}
One of the new perspectives on ageing is focused on the component opportunity - conquest of modern societies, which deconstructs the paradigm that is centred on the age variable. This paper aims at, based on national and international studies, contributing to the analysis of the transition models professional activity - retirement, highlighting the different factors that influence and differentiate these processes. Active ageing policies are analysed from an equal opportunity perspective, with special attention being drawn on the life trajectories before retirement, namely in the access to training. Another dimension of analysis that is framed by the international recommendations and orientations on these matters is the guarantee of the right to a dignifying and secure ageing, as a project of a long-lasting adulthood, which includes people in greater fragility.
\end{abstract}

Keywords: Opportunity, Empowerment, Project, Participation

\section{Envelhecimento Activo \\ - Que estratégia para a reforma?}

Envelhecer permanecendo activo constitui um dos desafios das sociedades modernas, tanto a nível individual como da sociedade. As opções individuais dependem em muito das oportunidades que, de forma organizada, são oferecidas no contexto em que cada um vai construindo o seu percurso e a sua identidade. Envelhecer permanecendo activo só pode ser entendido na perspectiva de "uma vida inteira" (Walker, 2002)

A reforma é um marco significativo do percurso de vida e a pós-reforma vem assumindo uma importância crescente na vida dos indivíduos. A saída cada vez mais precoce do mercado de emprego, transformou-a numa nova etapa, bem antes de chegarmos à velhice. Durante muito tempo, o marcador biológico da idade - a fadiga física - tinha uma relação directa com o marcador sociológico - a reforma. Hoje, as idades estão dessincronizadas: recuou o limite biológico, consequente às melhorias das condições de vida, ao mesmo tempo que avançou o limite sociológico, pela tendência à exclusão do mercado de emprego a partir dos 50 anos.

A reforma pode marcar um processo de isolamento social e de desvalorização individual, definido como (des) investimento, gerador de perda do sentido de relação com a sociedade (Guillemard, 1991) ou, ao contrário, iniciar uma recomposição activa dos papéis sociais. A par das estratégias centradas na vida familiar e no consumo (passagem de produtor 
na vida activa a reformado consumidor), outras podem orientar-se para o investimento numa forma de actividade criadora, socialmente reconhecida, funcionando como estruturante da actividade do sujeito, tal como o tinha sido a actividade profissional. As condições e hábitos de vida ao longo da existência e, em especial, o período a montante da reforma, têm um papel determinante neste processo. Mas, para todos, a saída do mercado de trabalho corresponde a um repensar e repensar-se face à família, aos amigos, à sociedade.

\section{A transição trabalho/reforma e o Direito a Envelhecer com Dignidade e Segurança}

A transição actividade profissional/reforma, o pós reforma e a velhice, correspondem a percursos cada vez mais longos, mais heterogéneos e mais diferenciados, em que a variável género tem expressão significativa. As saídas mais precoces das mulheres da vida profissional aparecem associadas a razões de desemprego, saúde ou obrigações familiares, factores que estruturam também períodos de transição pela via da protecção do desemprego e da doença para um número significativo de pessoas entre os 50 e 64 anos. Assim, se no caso das mulheres estamos perante fortes descontinuidades nas carreiras profissionais e contributivas com repercussões na situação pós reforma, a "espera pela reforma" através da protecção do desemprego ou da doença, significa um período de transição igualmente marcado por desigualdades de acesso ao emprego e à qualificação profissional que não deixarão de influenciar negativamente a nova etapa da vida que se aproxima. Tendências igualmente observadas entre países da OCDE e da UE. Poderemos perguntarmo-nos se o sucesso e/ou a simples possibilidade de investir na recomposição dos papéis, como já referimos, não poderá ser posto em causa se se acentuar ou persistir a divergência entre a idade social "medida" pelo estatuto com que a sociedade reconhece e dá valor a cada indivíduo, e a idade social/geração (capital de conhecimento temporalmente significante) que não deixa de acompanhar o relógio da idade.

Segundo Walker, o que está em causa é uma visão estratégica global, flexível, preventiva e participativa da orientação política neste domínio, a qual, e citamos,

\footnotetext{
"deve assumir um equilíbrio entre direitos e obrigações. Por outras palavras, esta estratégia deve ser multidimensional, aplicável ao indivíduo e à sociedade, de forma integrada. Os indivíduos devem tirar partido das possibilidades de educação permanente e de formação contínua, promover a sua própria saúde e bem-estar ao longo de toda a vida" (Walker, 2002).
}

O conceito de envelhecimento activo. EnveIhecer com projecto. O reconhecimento do valor do Sujeito.

Em 2000, a OCDE definiu envelhecimento activo como:

\footnotetext{
"(..) a capacidade das pessoas que avançam em idade terem uma vida produtiva na sociedade e na economia. O que quer dizer que possam determinar a forma como repartem 0 tempo entre as actividades de aprendizagem, o trabalho, o lazer e os cuidados a outros." (OCDE, 2000).
}

Conceito que rompe com os parâmetros etários com que temos trabalhado as questões do envelhecimento, alargando-os a outros patamares da vida adulta, com especial relevância para o período a montante da reforma.

Capacidades, iniciativa, planeamento da nova fase que se avizinha, enquadram uma nova concepção do envelhecer nas nossas sociedades, emergindo como projecto que abre janelas para um horizonte de vida que se prolonga. Ao conferir sentido para os indivíduos, é também detonador do sentido que a sociedade dá a esta oportunidade de viver mais anos. Ter acesso ao conhecimento e à formação são sinais do valor que se confere à cidadania, à identidade, ao reconhecimento e à valorização das experiências individuais.

Ou seja, uma estratégia de envelhecimento activo reportará sempre à promoção da igualdade de oportunidades e da não discriminação pela idade e por género no acesso à qualificação, ao emprego e à formação.

O Tratado de Amesterdão, (1997) ao determinar a eliminação das formas de segregação pela idade, (art.13), e ao consignar a necessidade de garantir a inclusão de todos, promovendo as medidas de discriminação positiva necessárias à não exclusão social dos mais desfavorecidos seja qual for a

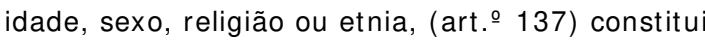
um instrumento vinculativo da orientação política neste domínio.

No mesmo sentido, as recomendações da $2^{\text {a }}$ Assembleia Mundial sobre o Envelhecimento, explicitam, com o mesmo sentido, o princípio da

\footnotetext{
“(...) participação na vida social, económica
} e política, a par do acesso a oportunidades de emprego, com horários e condições de trabalho adequadas, protecção adequada das pessoas idosas mais pobres, no respeito pela sua dignidade e integridade, protecção contra as formas de exploração de que podem ser alvo, assegurando o respeito pelos seus direitos fundamentais." (ONU, 2002) 
Todas estas razões conferem à formação um papel central. Ela permite partilhar o património cultural, científico e técnico quotidianamente construído, contraria fenómenos de exclusão social e é factor de desenvolvim ento das competências sociais com que participamos na sociedade. Assim sendo, as questões metodológicas da formação, "geragogia", têm ocupado formadores e cientistas. Resultados de estudos recentes nos EUA (EDUCATION AND AGEING, 2002, ED. TRIANGLE: 8-12) revelam que modelos que enfatizam a implicação nos processos de aprendizagem têm efeitos benéficos no bem-estar dos seniores, ao nível da auto-estima e da situação de saúde. Dão importância à equidade e à não competição, com forte ancoragem na experiência da aprendizagem. São conceptualizados como estratégia de soluções num contexto de rápida mudança demográfica, procurando romper com estereótipos associados à idade, ao desfavorecimento e à vitimização das pessoas que avançam em idade. A formação é considerada uma oportunidade para a construção do envelhecim ento como experiência positiva, mais consentânea com a conquista da longevidade que marca o século XXI.

A problemática da formação ao longo da vida não é certamente alheia a estas novas formas de abordagem. Estas são o corolário das preocupações com a educação e formação das pessoas com mais de 50 anos, claramente associadas às questões do emprego ou tão-somente à manutenção de uma actividade profissional, social ou cultural.

\section{O envelhecimento activo - estratégia de inserção social dos indivíduos e estratégia de coesão social nas sociedades fortemente envelhecidas}

O envelhecimento activo, enquanto estratégia de inserção social, é essencialmente uma experiência individual que assenta na possibilidade dos indivíduos poderem optar por manter uma actividade remunerada ou não, mantendo assim a sua ligação à sociedade em geral e à sua comunidade, em particular.

Mas o envelhecimento activo tem representado também uma estratégia de governação dos sistemas de segurança social, em especial na Europa, de forma a retardar e/ ou a evitar as saídas precoces do mercado de emprego. A arquitectura dos sistemas de protecção social adequada a um ciclo de vida que se reestrutura e se alonga, não pode deixar de acolher uma estratégia de envelhecimento activo/direito a envelhecer com dignidade e segurança. O que é certamente indissociável de soluções que combinem o estímulo ao emprego e à melhoria das qualificações sociais, à protecção social e aos direitos e condições de trabalho decente (Fernandes; Graça, 2007). Ou seja: combinar a oferta de emprego com formação, eliminando as formas de segregação pela idade, como se determina no Tratado de Amesterdão.

O acesso à formação é um factor estruturante deste processo. Dados sobre a procura e a oferta de diferentes tipos de formação são indicativos da procura não só de competências profissionais mas também de melhorias ao nível das competências pessoais e sociais.

Trabalho recente da Comissão Europeia (European Commission, 2006) dá conta da participação das pessoas dos diferentes grupos de idades na formação. A média europeia ( 25 países) é de $50 \%$ para o grupo 24-34 anos e 30\% para o grupo 55-64 anos, apresentando Portugal percentagens superiores, respectivamente $54 \%$ e $33 \%$, embora no que concerne à educação permanente associada à formação no grupo 25-64, as percentagens sejam menos favoráveis para Portugal quando comparadas com a Finlândia, França, Alemanha, Holanda e Inglaterra. As médias destes países estão entre $46 \%$ e $50 \%$ na formação contínua (1999), não ultrapassando Portugal $17 \%$. Aliás, a participação dos trabalhadores do grupo de idades 55-64 na formação situava-se em $7,4 \%$, no caso português (Fernandes; Graça, 2007). Da mesma forma, os dados do Third European Survey on Working Conditions 2000 (European Commission, 2006: 105) situam Portugal a grande distância destes países. De acordo com a mesma fonte, Portugal apresenta situação bem desfavorável em termos de qualificações acima do secundário nos diferentes grupos de idades $135 \%$ no grupo $25-34,20 \%$ no grupo $35-44,14 \%$ no grupo 45-54 e $8 \%$ no grupo 55-64, sendo que a média da OCDE é respectivamente $75 \%, 69 \%, 61 \%$ e $50 \%$, próximas das médias da maioria dos países europeus). Ou seja, estamos perante o desafio de um esforço acrescido neste domínio, por todas as razões, e também pela necessidade de favorecer 0 bem envelhecer de todas as gerações.

A análise das preferências, das escolhas dos mais velhos e dos mais novos face à procura de formação informal e não formal sugere algumas interrogações. Segundo dados do trabalho que vimos referenciando, Portugal apresenta as maiores percentagens da participação na formação informal segundo a idade e o nível de escolarização: nos grupos de idades 25-34, 45-54 e 55-64, quer se trate de nível elevado de escolarização ou de baixo nível de escolarização. Em sentido contrário se comporta a participação na formação não formal considerada em função do estatuto socioprofissional: Portugal apresenta índices significativamente mais baixos que a média da UE (25) em todos os níveis considerados. Interessante é todavia salientar que as percentagens mais elevadas observadas (média UE) se reportam às categorias socioprofissionais mais elevadas, os "colarinhos brancos", tendência igualmente verificada para Portugal. 
Quererá isto significar diferenças entre iniciativas individuais e as que decorrem dos contextos de emprego? Quererá significar maior investimento individual na melhoria das competências sociais, em especial dos que detêm nível socioprofissional mais elevado? Revelará menor interesse dos empregadores nesta área?

Questões em aberto a merecerem estudo aprofundado e que não são certamente displicentes para a análise da qualidade do percurso de vida dos indivíduos. São questões associadas à gestão das carreiras e têm especial importância para os trabaIhadores seniores, confrontados com o imperativo de "converter a sua experiência em potencial", ou seja, como refere Réguer, "construir um projecto profissional de acordo com o seu projecto de vida" (Réguer, 2007). Na situação específica de fim de carreira, ao relativizar os limites impostos valorizando outras dimensões, poderá facilitar a recomposição dos papéis, com efeitos num registo positivo do envelhecimento.

\section{A preparação para a reforma \\ - planear o futuro. Estruturar um projecto, gerir os riscos e antecipar soluções}

O projecto de uma vida adulta prolongada revela-se um desafio pessoal - quem sou eu, onde estou, para onde vou (Pereira, 2004). É exigente: exige esforço, é expressão de liberdade e de autonomia, está associado ao conceito de progresso, tenta controlar o futuro, altera a percepção do tempo e permite encarar a realidade como relacional.

Alguns teóricos do Proactive Ageing (Kahana et al., 2003) identificaram comportamentos que classificaram como mais favoráveis quer à reconstrução dos laços sociais quer dos papéis e dos estatutos, com efeitos positivos no envelhecimento e na prevenção dos riscos: riscos sociais (isolamento e solidão); riscos ambientais (barreiras, habitação desadequada); riscos de saúde (incapacidades e dependências).

Esquematicamente, agrupam-nos em dois grandes grupos que "resultam do entrosamento entre o potencial do indivíduo e as oportunidades que $o$ colectivo oferece" (Kahana et al., 2003)

- Internos (auto-estima, capacidade de relação com os outros, satisfação pessoal).

- Externos (rendimentos, redes de inserção, acesso à tecnologia, acesso aos cuidados de saúde, a serviços de proximidade).

Os primeiros estão associados às redes de sociabilidade, intergeracionais e intrageracionais. Umas e outras são da maior relevância na prevenção da solidão e isolamento social. As relações intergeracionais inscrevem-se essencialmente no círculo familiar, mas abrangem hoje outras formas de convivência que podem reforçar o sentido da utilidade social dos mais velhos e o reconhecim ento do seu papel na sociedade, como é o caso das actividades de voluntariado. A par destas formas de sociabilidade, e acompanhando escolhas de projecto nesta fase da vida, emergem as relações horizontais, numa lógica de associação por interesses, afinidades e pertença geracional. Constituem redes de suporte extra familiares, sustentam e viabilizam a participação cívica e cultural, entre as quais as associações de reformados e as academias seniores são expressões relevantes.

A segunda ordem de factores enunciados é essencialmente da responsabilidade colectiva. Inserem-se, por um lado, no quadro da oferta de oportunidades e, por outro lado, na esfera da protecção social: preventiva, curativa e reparadora.

Globalmente, reforçam claramente a componente preventiva, pondo em evidência a necessidade de investimento na informação e na formação como estratégia de empoderamento dos indivíduos que avançam em idade e fazem a transição trabalho profissional/reforma. Valorizam o papel social, económico e cultural destas pessoas, enfatizam a prevenção/controle dos riscos ao longo do percurso de vida, sem minimizar a protecção dos riscos.

Garantir dignidade e segurança no processo de envelhecer revela-se, pois, indissociável da valorização do desenvolvimento das capacidades e das competências sociais dos indivíduos, reconhecimento a que cada pessoa tem direito.

$\mathrm{Na}$ senda destas reflexões, os resultados da investigação desenvolvida no âmbito do projecto Paquid (Pérès e Barberger-Gateau, 2001) são consistentes com o que vimos referindo: as pessoas mais escolarizadas estão duas vezes mais representados entre as pessoas autónomas mais velhas. O que nos permite afirmar que os níveis de autonomia e de bem-estar nas idades avançadas estão associados a melhores níveis de escolarização e de participação social.

Ou seja, à medida que avançam os no conhecimento sobre o envelhecim ento humano, mais vamos sabendo sobre a importância do desenvolvimento das capacidades individuais na qualidade destes processos. A própria experiência de envelhecimento activo vem pondo em evidência a relevância deste factor, o que certamente constituirá uma exigência acrescida para todos os que no seu quotidiano põem o seu saber e experiência ao serviço dos mais velhos e dos que vão envelhecendo.

Ao consideramos o desenvolvimento das capacidades individuais como factor determinante da qualidade do envelhecer, num contexto de heterogeneidade crescente dos contextos, dos percursos e das vivências, envelhecimento activo não deve 
nem pode ser confundido com novos estereótipos, nem ser confinado a modelos preestabelecidos. Seja qual for o contexto em que cada um se encontra ou as dificuldades e défices que o limitam, envelhecer activamente continua a ser uma exigência pessoal e colectiva. Melhorar as competências sociais, valorizar a criatividade, centrar a intervenção no sujeito, oferecer serviços de qualidade, adequados e em tempo útil, são estratégias de promoção da autonomia a accionar na intervenção em situações de dependência.

Ou seja, uma estratégia global deve necessariamente ter em conta a persistência de desigualdades pessoais e espaciais que afectam sobretudo as gerações mais idosas (elevados índices de pobreza associada a problemas de habitat, a défices de acesso a serviços de proximidade com qualidade, a problemas de saúde e a isolamento), as quais reforçam a componente reparadora/inclusiva da protecção social da velhice, tanto melhor sucedida quanto mais integrar uma lógica de empoderamento contrariando uma lógica assistencialista.

Por outras palavras, importa não "entrar" por uma nova dicotomia velhice autónoma/velhice dependente, reforçando velhos estereótipos, medos e irracionalidades face ao envelhecimento e à velhice.

Em síntese, num contexto sem paralelo na história, em que perspectivas de melhorias significativas da esperança de vida se abrem para biliões de pessoas no planeta, os benefícios previsiveis do envelhecer bem e da constituição do fantástico potencial humano decorrente do aumento substancial do número de adultos mais velhos, é um dado que não pode ser negligenciado. Ao contrário, valorizá-lo como oportunidade constitui um desafio para a decisão politica e para a sociedade. As associações de reformados e seniores que por toda a parte se vão constituindo são reveladores deste potencial. Em Portugal o seu desenvolvimento, em especial nos últimos cinco anos, é expressão de uma extraordinária vitalidade, motora em muitos casos de processos de genuína intergeracionalidade.

Para os indivíduos, os desafios são os da organização do percurso de vida, na aventura do ser e do fazer, do projectar-se num tempo que se alonga e num espaço que a todos tende a aproximar. Enfrentá-los com sucesso é indissociável da capacidade das sociedades integrarem a componente envelhecimento como estruturante do seu desenvolvimento e do seu porvir.

Envelhecer de forma activa tece-se nas malhas das relações que constituem o nosso quotidiano, reforça os laços sociais e exorciza o isolamento e a solidão.

Envelhecer ou a vida a inventar, como propõe, Lalive D’Épinay, será o contributo para (re) inventar a sociedade do séc. XXI, na solidariedade e no conhe- cimento "que procure o que nos pode juntar e unir num projecto comum" (Lalive D’Épinay, 1991)

O movimento do presente para o futuro, quer dizer, a acção mesma, é induzido pelos valores, crenças, fins e ideais que o sujeito prossegue.

O tempo vivido é a consciência mesma da acção porque é a consciência actual de desejar um futuro concebido como desejável.

Cyrulnik et al., 2006

\section{Referências bibliográficas}

CENTENO, L.G. (2006), "Envelhecimento e barreiras da idade no emprego", Cadernos Sociedade e Trabalho, 7, pp. 155-178.

CÔRTE, B. et al. (2006), Envelhecimento e velhice, um guia para a vida, S. Paulo, Vetor Editora.

CYRULNIK, B. et al. (2006), Penser le temps pour lire la vieillesse, Paris, Fondation Eisai / PUF.

DRANDEL, J.P. (2003), Le Pouvoir Gris, Paris, PUF.

EUROPEAN COMISSION (EC) (2006), Ageing and employment: identification of good practice to increase job opportunities and maintain older workers in employment final report, http://ec.europa.eu/ employment_social/news/2006/sept/ageingreport_en.pdf.

FERNANDES, A. A. e S. Graça (coords.) (2007), EnveIhecimento e Perspectivas de Criação de Emprego e Necessidades de Formação para a Qualificação de Recursos Humanos, Lisboa, Instituto do Emprego e Formação Profissional, Estudos, 37.

GUILLEMARD, A.-M. (1991), La retraite en mutation, Paris, FEN IRES.

GUILLEMARD, A.-M. (1980), La Vieillesse et l'Etat, Paris, Puf.

HENRARD, J.-C. (2002), Les Défis Du Vieillissement, Paris, La Découverte.

KAHANA, E., B. Kahana e K. Kercher (2003), "Emerging lifestyles and proactive options for successful ageing", Ageing International, 28 (2), pp. 155-180.

LALI VE D'ÉPINAY, C. (1991), Vieillir ou la vie à inventer, Paris, Editions L'Harmattan.

LEVET, M. (2002), Les Valeurs de l'âge, Ramonville Saint-Agne, Érès.

ORGANISATION DE COOPERATION ET DE DEVELOPPEMENT ECONOMIQUES (2000), "Des Réform es Pour Une Société Vieillissante", SourceOCDE Questions sociales/Migrations/Santé (Vol. 2000).

PEREIRA, M. (2004), "Projecto de vida em anciania", Futurando, 11, 12 e 13.

PÉRÈS K. e P. Barberger-Gateau (2001), "Évolution de l'incapacité entre 75 et 84 ans: suivi de deux générations à travers l'enquête Paquid", Gérontologie et Société, 98, pp. 49-64.

PUIJALON, B. e J. Trincaz (2000), Le Droit De Vieillir, Paris, Fayard. 
QUARESMA, M. L., A. A. Fernandes, D. Ferreira e M. Pereira (2004), O Sentido das idades da vida, interrogar a solidão e a dependência, Lisboa, CESDET.

QUARESMA, M.L. (2005), "Envelhecimento e projecto de vida", Futurando, 11, 12 e 13.

QUARESMA, M.L. e S. Graça (2006), "A Evolução das aspirações e necessidades da população envelhecida novas perspectivas de actuação e intervenção", Cadernos Sociedade e Trabalho, 7, pp. 179-198.

REGUER, D. (org.) (2007), Vieillissement et parcours de fin de carrière: contraintes et stratégies, Ramonville Saint-Agne, Érès.
SCHLEI ERMACHER, F. (2006), Le Réveil de Mathusalem: l'avenir appartient a ceux qui savent vieillir, Paris, Robert Lafont.

UNITED NATIONS - ECONOMIC AND SOCIAL COUNCIL (2002), Regional Implementation strategy for the Madrid Internacional Plan of Action on Ageing 2002, UNECE Ministerial Conference on Ageing Berlin (Germany), 11-13 September 2002, http://www. minvws.nl/en/kamerstukken/zzoude_directies/ dvvo/2002/regional-implementation-strategyfor-the-madrid-international-plan-of-action-onaging.asp.

WALKER, A. (2002), "Une stratégie pour vieillir en restant actif", Revue internationale de sécurité sociale, 55 (1), pp. 143-165. 